Jurnal Media Agribisnis Vol. 4 No. 1 Tahun 2019 Hal 10 - 20

Media Komunikasi Hasil Penelitian Bidang Ilmu Agribisnis

ISSN print 2548-7027

ISSN online 2541-6898

\title{
PERBEDAAN PENDAPATAN PETANI KEDELAI PESERTA DAN NON \\ PESERTA PROGRAM UPSUS (UPAYA KHUSUS) DI KECAMATAN RANTAU RASAU KABUPATEN TANJUNG JABUNG TIMUR
}

\author{
${ }^{1)}$ Rizki Gemala Busyra dan ${ }^{2)}$ Risanuddin \\ ${ }^{1)}$ Dosen Program Studi Agribisnis, Fakultas Pertanian Universitas Batanghari \\ ${ }^{2)}$ Alumni Program Studi Agribisnis Fakultas Pertanian Universitas Batanghari \\ J1. Slamet Riyadi, Broni Jambi. 36122. Telp. +62074160103 \\ ${ }^{1)}$ Email korespondensi: rizki.gemala.busyra@unbari.ac.id
}

\begin{abstract}
Rantau Rasau District, East Tanjung Jabung Regency is one of the areas in Jambi Province that implements UPSUS programs. It was not all farmer groups had joined the UPSUS program. The research objective was to Calculate the income of soybean farmers inside and outside of the UPSUS program. The statistical test used in this study was "independent sample $t$ test". The results of the study showed that the income of soybean farming inside the UPSUS program was higher than that the outside one, where the farmer average income inside the UPSUS program was Rp. 8.753.145/Ha/periode and outside the UPSUS program amounting to $R p$. 1.256,431/Ha/periode. There was a significant difference between those income above. The average of soybean yield inside the UPSUS program was $2206.45 \mathrm{Kg} / \mathrm{Ha} /$ periode with a selling price as $\mathrm{Rp} .6 .500 / \mathrm{Kg}$. Hence the revenue of the farmer inside the program was Rp. 14.341.935/Ha/periode. While the farmer outside the UPSUS program showed lower yield as 1129.03 $\mathrm{Kg} / \mathrm{Ha} /$ periode with its price as $\mathrm{Rp} .6 .000 / \mathrm{Kg}$, hence its revenue was $\mathrm{Rp}$. 6.886.784/Ha/periode.
\end{abstract}

Keywords: Revenue, UPSUS, Non UPSUS

\begin{abstract}
Abstrak
Kecamatan Rantau Rasau Kabupaten Tanjung Jabung Timur merupakan salah satu wilayah dalam propinsi Jambi yang menerapkan kegiatan atau program UPSUS. Belum semua kelompok tani mengikuti program UPSUS. Tujuan Penelitian adalah untuk menghitung pendapatan petani kedelai peserta dengan non perserta program UPSUS. Uji statistik yang digunakan dalam penelitian ini adalah Uji Beda rata-rata atau Uji Z. Hasil penelitian menunjukkan bahwa pendapatan usaha tani kedele untuk petani peserta UPSUS lebih tinggi dibanding dengan petani Non UPSUS, yaitu rata-rata pendapatan petani UPSUS adalah sebesar Rp. 8.753.145/Ha/MT dan petani Non UPSUS sebesar 1.256.431/Ha/MT. Terdapat perbedaan signifikan antara ke-2 pendapatan tersebut di atas. Rata-rata hasil produksi kedele untuk petani peserta UPSUS sebanyak $2206,45 \mathrm{Kg} / \mathrm{Ha} / \mathrm{MT}$ dengan harga jual Rp.6.500/Kg. Rata-rata penerimaan sebesar Rp.14.341.935/Ha/MT, Sedangkan rata-rata hasil produksi kedele petani Non UPSUS menunjukkan lebih rendah yaitu 1129,03 Kg/Ha/MT dengan harga jual Rp.6.000/Kg, sehingga ratarata penerimaannya adalah Rp. 6.886.784/Ha/MT.
\end{abstract}

Kata Kunci : Pendapatan, UPSUS, Non UPSUS

Diterbitkan oleh Program Studi Agribisnis Fakultas Pertanian Universitas Batanghari Jambi Halaman 10 
Jurnal Media Agribisnis Vol. 4 No. 1 Tahun 2019 Hal 10 - 20

Media Komunikasi Hasil Penelitian Bidang Ilmu Agribisnis

ISSN print 2548-7027

ISSN online 2541-6898

\section{PENDAHULUAN}

Kedelai merupakan tanaman pangan utama strategis terpenting setelah padi dan jagung. Pada tahun 2016 produksi kedelai Provinsi Jambi sebesar 6.732 ton dengan luas lahan tanaman kedelai sebesar 4.906 ha dengan produktivitas sebesar 1,372 ton/ha. Jika dilihat dari produktivitas tanaman kedelai di Kabupaten yang ada di Provinsi Jambi, maka Kabupaten Tanjung Jabung Timur merupakan penyumbang terbesar ke-3 dengan total produksi kedelai sebesar 1.028 ton dengan produktivitas sebesar 1,508 ton/ha, nilai produktivitas ini lebih tinggi dibandingkan dengan produktivitas Provinsi Jambi yakni sebesar 1,372 ton/ha (BPS, 2015). Hal ini disebabkan Kabupaten Tanjung Jabung Timur merupakan salah satu sentra produksi kedelai di Provinsi Jambi dengan pemanfaatan lahan yang tinggi. Kecamatan Rantau Rasau menghasilkan produksi kedelai terbesar ke 2 setelah Kecamatan Berbak. Tingginya produksi kedelai di Kecamatan Berbak karena semua kelompok tani mengikuti program Upaya Khusus (UPSUS), sedangkan di Kecamatan Rantau Rasau masih sebagian yang mengikuti program UPSUS. Secara umum produksi kedelai tersebut harus terus ditingkatkan guna pencapaian swasembada pangan berkelanjutan yang telah ditetapkan oleh pemerintah.

Target produksi kedelai yang harus dicapai di Kabupaten Tanjung Jabung Timur pada tahun 2015 yaitu sebesar 1468 Ton, maka jumlah produksi kedelai di Kabupaten Tanjung Jabung Timur masih berada dibawah target pencapaian. Oleh karena itu Target tersebut akan terus ditingkatkan pada tahun 2016 dan 2017. Jika target peningkatan produksi kedelai tersebut tercapai maka akan meningkatkan sumbangsih subsektor tanaman pangan pada sektor pertanian yang selanjutnya akan meningkatkan pendapatan petani dan perekonomian daerah Kabupaten Tanjung Jabung Timur.

Salah satu upaya yang dilakukan pemerintah untuk meningkatkan produksi pangan nasional, adalah melalui program kegiatan pendampingan dan pengawalan. Kegiatan pengawalan dan pendampingan tersebut disebut sebagai kegiatan UPSUS (Upaya Khusus) peningkatan produksi tiga komoditas padi, jagung, dan kedelai (Pajale) (Busyra, 2016). Program Upsus dilaksanakan serentak di beberapa provinsi di Indonesia, termasuk di Provinsi Jambi.

Pelaksanaan program UPSUS tentu memberikan banyak manfaat dan perubahan yang positif guna meningkatkan produksi kedelai yang selanjutnya dapat meningkatkan pendapatan petani. Kecamatan Rantau Rasau merupakan salah satu wilayah dalam propinsi Jambi yang menerapkan kegiatan atau program UPSUS tersebut. Petani kedelai di Kecamatan Rantau Rasau tergabung dalam beberapa kelompok tani, namun belum semua kelompok tani mengikuti program UPSUS.

Keikutsertaan petani atau kelompok tani dalam program UPSUS tentunya akan memberikan dampak atau pengaruh terhadap pendapatan petani. Berdasarkan uraian tersebut diatas, maka perlu kiranya dilakukan penelitian dengan judul "Perbedaan Pendapatan Petani Kedelai Peserta dan Non Peserta Program UPSUS Di Kecamatan Rantau Rasau Kabupaten Tanjung Jabung Timur".

Diterbitkan oleh Program Studi Agribisnis Fakultas Pertanian Universitas Batanghari Jambi Halaman 11 
Jurnal Media Agribisnis Vol. 4 No. 1 Tahun 2019 Hal 10 - 20

Media Komunikasi Hasil Penelitian Bidang Ilmu Agribisnis

ISSN print 2548-7027

ISSN online 2541-6898

\section{METODOLOGI PENELITIAN}

Penelitian ini dilaksanakan di Kecamatan Rantau Rasau Kabupaten Tanjung Jabung Timur. Lokasi penelitian dipilih secara sengaja (purposive) dengan pertimbangan bahwa di Kecamatan Rantau Rasau merupakan salah satu wilayah dalam propinsi Jambi yang menerapkan kegiatan atau program UPSUS komoditas kedelai. Namun belum semua Petani kedelai di Kecamatan Rantau Rasau mengikuti program UPSUS.

Ruang lingkup penelitian meliputi gambaran kegiatan usahatani kedelai perserta dan non Perserta Program UPSUS, pendapatan petani kedelai perserta dan non perserta Program UPSUS, dan perbedaan pendapatan petani kedelai sebagai perserta dengan non perserta program UPSUS.

Penelitian dilakukan dengan metode survey yaitu mengunjungi dan mewawancarai petani perserta dan non peserta Program UPSUS kedelai. Data yang dipergunakan dalam penelitian ini dapat diklasifikasikan dan diperoleh dari dua sumber yaitu data primer dan data skunder.

Data Primer berupa data yang diambil langsung dari petani yang terpilih sebagai sampel, pengambilan data dilakukan dengan wawancara langsung pada responden dengan menggunakan daftar pertanyaan yang terpola dan terstruktur sesuai dengan kebutuhan.

Data Sekunder merupakan data tambahan yang dibutuhkan untuk melengkapi penelitian ini diperoleh dari berbagai intansi terkait, perpustakaan, publikasi ilmiah terutama yang relevan dengan masalah yang diteliti. Jenis data yang digunakan adalah data cross section.

Besarnya ukuran sampel yang diambil sesuai dengan pernyataan Winarno (2004), bahwa untuk pedoman umum saja dapat dikatakan bahwa bila populasi cukup homogen, terhadap populasi di bawah 100 dapat di gunakan sampel sebesar $50 \%$ dan bila populasi diatas 100 dapat diambil sampel sebesar $15 \%$.

Jumlah petani di Kecamatan Rantau Rasau yang mengkuti program UPSUS adalah sebanyak 162 orang sedangkan petani non peserta UPSUS sebanyak 174 orang. Menurut Winarno (2004), untuk sampel manusia hendaknya diatas 30 orang. Oleh karena itu maka jumlah sampel untuk petani peserta maupun non peserta program UPSUS adalah masing-masing sebanyak 31 orang, sehingga jumlah total sampel yang akan diambil adalah sebanyak 62 orang.

Untuk mengetahui gambaran kegiatan usahatani perserta dan non perserta program UPSUS di Kecamatan Rantau Rasau Kabupaten Tanjung Jabung Timur, maka data yang diperoleh dari hasil penelitian disederhanakan dengan cara tabulasi, frekuensi dan persentase kemudian dianalisis secara deskriptif baik kualitatif maupun kuantitatif. Sedangkan untuk menghitung pendapatan petani perserta dan non peserta program UPSUS di Kecamatan Rantau Rasau Kabupaten Tanjung Jabung Timur dengan cara yaitu total penerimaan dikurangi dengan total biaya. Menghitung total biaya digunakan rumus menurut Soekartawi (2000), yaitu pendapatan usahatani merupakan selisih antara penerimaan dan semua biaya (biaya tetap + biaya variabel).

Diterbitkan oleh Program Studi Agribisnis Fakultas Pertanian Universitas Batanghari Jambi Halaman 12 
Jurnal Media Agribisnis Vol. 4 No. 1 Tahun 2019 Hal 10 - 20

Media Komunikasi Hasil Penelitian Bidang Ilmu Agribisnis

ISSN print 2548-7027

ISSN online 2541-6898

$$
\boldsymbol{\pi}=\mathbf{T R}-\mathbf{T C}
$$

Dimana:

$$
\begin{array}{ll}
\pi & =\text { Pendapatan Usahatani }(\mathrm{Rp} / \mathrm{Ha} / \mathrm{MT}) \\
\mathrm{TR} & =\text { Total penerimaan }(\mathrm{Rp} / \mathrm{Ha} / \mathrm{MT}) \\
\mathrm{TC} & =\text { Total biaya }(\mathrm{Rp} / \mathrm{Ha} / \mathrm{MT})
\end{array}
$$

Selanjutnya untuk menghitung besarnya penerimaan dihitung dengan mengunakan rumus sebagai berikut :

Dimana:

$$
\mathbf{T R}=\mathbf{Y} . \mathbf{P y}
$$

$$
\begin{array}{ll}
\mathrm{TR} & =\text { Total penerimaan }(\mathrm{Rp} / \mathrm{Ha} / \mathrm{MT}) \\
\mathrm{Y} & =\text { Produksi suatu usaha tani kedelai }(\mathrm{Kg} / \mathrm{HaMT}) \\
\mathrm{Py} & =\text { Harga kedelai }(\mathrm{Rp} / \mathrm{Kg}) \\
1 \mathrm{MT} & =100 \text { hari }(3 \text { bulan })
\end{array}
$$

Untuk menghitung pendapatan petani kedelai program UPSUS yaitu total penerimaan di kurangi dengan total biaya, untuk menghitung total biaya mengunakan rumus menurut Soekartawi (2000) sebagai berikut :

$$
\mathbf{T C}=\mathbf{F C}+\mathrm{VC}
$$

Dimana :

TC : Total biaya produksi kedelai (pengeluaran) $(\mathrm{Rp} / \mathrm{Ha} / \mathrm{MT})$

FC : Fixed cost atau biaya tetap $(\mathrm{Rp} / \mathrm{Ha} / \mathrm{MT})$

$\mathrm{VC}$ : Variabel cost atau biaya tidak tetap ( $\mathrm{Rp} / \mathrm{Ha} / \mathrm{MT})$

Biaya penyusutan dihitung menggunakan metode garis lurus dengan rumus menurut (Syafri, 2002) yaitu :

$$
D=\frac{C-S}{N}
$$

Dimana :

$$
\begin{array}{ll}
\mathrm{D} & =\text { Biaya penyusutan alat }(\mathrm{Rp} / \mathrm{Ha} / \mathrm{MT}) \\
\mathrm{C} & =\text { Harga awal alat }(\mathrm{Rp}) \\
\mathrm{S} & =\text { Harga akhir alat }(\mathrm{Rp}) \\
\mathrm{N} & =\text { Perkiraan umur ekonomis (Bulan) } \\
\text { Dengan asumsi } S=0
\end{array}
$$

Untuk melihat perbedaan tingkat pendapatan petani perserta dengan non perserta pogram UPSUS di gunakan uji beda dua rata-rata (Uji z ) menurut (Djarwanto dan Subagyo, 1993) dengan formulasi sebagai berikut:

$$
\begin{gathered}
z=\frac{\left(\overline{x_{1}}-\overline{x_{2}}\right)}{\sqrt{\frac{S_{1}^{2}}{n_{1}}+\frac{S_{2}^{2}}{n_{2}}}} \\
S_{x_{i}}^{2}=\frac{\sum x_{x_{1}}^{2}-\frac{\left(\sum x\right)^{2}}{n_{x}}}{n_{x}}
\end{gathered}
$$

Diterbitkan oleh Program Studi Agribisnis Fakultas Pertanian Universitas Batanghari Jambi Halaman 13 
Jurnal Media Agribisnis Vol. 4 No. 1 Tahun 2019 Hal 10 - 20

Media Komunikasi Hasil Penelitian Bidang Ilmu Agribisnis

ISSN print 2548-7027

ISSN online 2541-6898

Dimana:

$n_{1}=$ Jumlah sampel dari usaha tani kedelai yang ikut program UPSUS

$n_{2}=$ Jumlah sampel dari usaha tani kedelai yang tidak ikut program UPSUS

$\overline{x_{1}}=$ Rata-rata pendapatan bersih dari petani yang ikut program UPSUS

$\overline{x_{2}}=$ Rata-rata pendapatan bersih petani yang tidak ikut dalam program UPSUS

$S_{1}^{2}=$ Varian sampel petani yang ikut dalam program UPSUS

$S_{2}^{2}=$ Varian sampel petani yang yang tidak ikut dalam program UPSUS

$\sum \mathrm{x}=$ Jumlah total pendapatan petani sampel

$n_{\mathrm{x}}=$ jumlah petani yang dijadikan sampel

Hipotesis stastistik : $(\alpha=5 \%)$

Ho $: \mathrm{X} 1=\mathrm{X} 2$

$\mathrm{H} 1 \quad: \mathrm{X} 1 \neq \mathrm{X} 2$

Dimana: X1 : Rata-rata pendapatan usahatani kedelai untuk petani peserta UPSUS

X2 : Rata-rata pendapatan usahatani kedelai untuk petani Non peserta UPSUS

Untuk mengambil keputusan, maka nilai $\mathrm{Z}$ hitung akan dibandingkan dengan nilai $Z$ tabel dimana kaidah keputusannya adalah :

Ho ditolak jika $\quad:-\mathrm{Z} \alpha \geq \mathrm{Zhit} \geq \mathrm{Z} \alpha$

Ho diterima jika $\quad:-\mathrm{Z} \alpha<$ Zhit $<\mathrm{Z} \alpha$

Dimana nilai $Z_{\text {tabel }}$ pada $1 / 2 \alpha=0,025$ adalah sebesar 1,96 , sehingga hipotesis operasional yang diajukan adalah :

Ho: Tidak terdapat perbedaan pendapatan petani UPSUS dengan petani Non UPSUS.

$\mathrm{H}_{1}$ : Terdapat perbedaan pendapatan petani UPSUS dengan petani Non UPSUS.

\section{HASIL DAN PEMBAHASAN}

\section{Identitas Petani}

\section{Umur Petani}

Jumlah petani sampel berdasarkan kelompok umur di daerah penelitian yang ikut serta sebagai peserta program UPSUS dan Non UPSUS dapat dilihat pada Tabel 1.

Data pada Tabel 1 diketahui bahwa umur petani sampel yang ikut serta sebagai peserta program UPSUS berkisar antara $30-78$ tahun. Umur petani sampel terbanyak yaitu pada kelas interval 30 - 37 tahun dengan jumlah petani sebanyak 12 RTP atau sebesar 39\%, dan kelas interval terendah yaitu 46 - 53 dengan jumlah petani sampel sebanyak 2 RTP atau sebesar $6 \%$.

Diterbitkan oleh Program Studi Agribisnis Fakultas Pertanian Universitas Batanghari Jambi Halaman 14 
Jurnal Media Agribisnis Vol. 4 No. 1 Tahun 2019 Hal 10 - 20

Media Komunikasi Hasil Penelitian Bidang Ilmu Agribisnis

ISSN print 2548-7027

ISSN online 2541-6898

Tabel 1. Distribusi Frekuensi Petani Sampel Berdasarkan Kelompok Umur Di Daerah Penelitian sebagai peserta program UPSUS.

\begin{tabular}{ccccccc}
\hline No. Kelas & Umur & $\begin{array}{c}\text { Frekuensi } \\
(\text { RTP })\end{array}$ & $\begin{array}{c}\text { Frekuensi } \\
\text { relatif }(\%)\end{array}$ & Umur & $\begin{array}{c}\text { Frekuensi } \\
(\text { RTP })\end{array}$ & $\begin{array}{c}\text { Frekuensi } \\
\text { relatif }(\%)\end{array}$ \\
\hline 1 & $30-37$ & 12 & 39 & $30-36$ & 6 & 19 \\
2 & $38-45$ & 3 & 10 & $37-43$ & 8 & 26 \\
3 & $46-53$ & 2 & 6 & $44-50$ & 4 & 13 \\
4 & $54-61$ & 5 & 16 & $51-57$ & 5 & 16 \\
5 & $62-69$ & 4 & 13 & $58-64$ & 6 & 19 \\
6 & $70-77$ & 5 & 16 & $65-71$ & 2 & 6 \\
\hline Jumlah & $\mathbf{3 1}$ & $\mathbf{1 0 0}$ & & $\mathbf{3 1}$ & $\mathbf{1 0 0}$ \\
\hline
\end{tabular}

Sumber : Data Primer yang diolah, 2017

Data pada Tabel 1 menunjukkan bahwa petani sampel didominasi pada kelompok umur atau kelas interval 37 - 43 tahun dengan jumlah sebanyak 8 RTP atau sebesar $26 \%$, dan kelas interval terendah terdapat pada kelompok umur 65 71 tahun yaitu sebanyak 2 RTP atau sebesar 6\%. Artinya petani UPSUS dengan rata-rata umur 49,68 tahun dan petani Non UPSUS yaitu 47,68 tahun termasuk golongan umur yang produktif untuk melakukan pekerjaaan. Pada kisaran umur tersebut umumnya sudah banyak menikah, yang mendorong responden untuk bekerja (Febriyastuti $\mathrm{R}$ et al, 2016).

\section{Tingkat Pendidikan}

Data pada Tabel 2 menunjukkan bahwa tingkat pendidikan petani sampel yang mengikuti program UPSUS mayoritas berpendidikan SD dengan jumlah sebanyak 19 RTP atau 61,3\%. Sedangkan tingkat pendidikan petani sampel yang Non UPSUS mayoritas berpendidikan SD dengan jumlah sebanyak 19 RTP atau $61 \%$. Tingkat pendidikan petani sampel tergolong rendah, sehingga dengan rendahnya tingkat pendidikan diperlukan solusi teknis untuk mengatasinya, petani dengan umur yang sudah tua tidak mungkin lagi akan duduk di bangku sekolah, salah satu solusinya adalah dengan mengikutkan para petani tersebut pada program pelatihan, penyuluhan dan lain-lain. Semakin tinggi tingkat pendidikan seseorang, semakin berkembang pola berpikirnya sehingga dapat dengan mudah mengambil keputusan dalam melakukan sesuatu dengan baik (Subagio $\mathrm{H}$ et al, 2016).

Tabel 2. Distribusi Frekuensi Petani Sampel Berdasarkan Tingkat Pendidikan Di Daerah Penelitian sebagai peserta program UPSUS

\begin{tabular}{|c|c|c|c|c|c|c|}
\hline \multirow[b]{2}{*}{$\begin{array}{l}\text { No. } \\
\text { Kelas }\end{array}$} & \multicolumn{3}{|c|}{ UPSUS } & \multicolumn{3}{|c|}{ NON UPSUS } \\
\hline & $\begin{array}{c}\text { Kelas } \\
\text { Interval }\end{array}$ & Frekuensi & $\begin{array}{l}\text { Frekuensi } \\
\text { relatif }(\%)\end{array}$ & Kelas Interval & Frekuensi & $\begin{array}{l}\text { Frekuensi } \\
\text { relatif }(\%)\end{array}$ \\
\hline 1 & SD & 19 & 61,3 & Tidak Tamat SD & 9 & 29 \\
\hline 2 & SMP & 10 & 32,3 & SMP & 19 & 61 \\
\hline 3 & SMA & 2 & 6,5 & SMA & 3 & 10 \\
\hline Jumlah & & 31 & 100 & & 31 & 100 \\
\hline
\end{tabular}

Sumber: Data primer yang diolah, Tahun 2017

Diterbitkan oleh Program Studi Agribisnis Fakultas Pertanian Universitas Batanghari Jambi Halaman 15 
Jurnal Media Agribisnis Vol. 4 No. 1 Tahun 2019 Hal 10 - 20

Media Komunikasi Hasil Penelitian Bidang Ilmu Agribisnis

ISSN print 2548-7027

ISSN online 2541-6898

\section{Pengalaman Berusahatani Petani Sampel}

Pengalaman kerja akan mempengaruhi sistem pengelolaan kegiatan berusaha tani, dimana petani yang sudah berpengalaman biasanya memiliki hasil produksi yang baik. Data distribusi dan frekuensi petani sampel berdasarkan pengalaman berusahatani kedelai dapat dilihat pada Tabel 3 .

Tabel 3. Distribusi dan Frekuensi Petani UPSUS Sampel Berdasarkan Pengalaman.

\begin{tabular}{ccccccc}
\hline \multirow{2}{*}{$\begin{array}{c}\text { No. } \\
\text { Kelas }\end{array}$} & \multicolumn{3}{c}{ UPSUS } & \multicolumn{3}{c}{ NON UPSUS } \\
\cline { 2 - 7 } & Pengalaman & Frekuensi & $\begin{array}{c}\text { Frekuensi } \\
\text { relatif }(\%)\end{array}$ & Pengalaman & Frekuensi & $\begin{array}{c}\text { Frekuensi } \\
\text { relatif }(\%)\end{array}$ \\
\hline 1 & $10-13$ & 4 & 13 & $8-10$ & 8 & 26 \\
2 & $14-17$ & 1 & 3 & $11-13$ & 3 & 10 \\
3 & $18-21$ & 22 & 71 & $14-16$ & 4 & 13 \\
4 & $22-25$ & 2 & 6 & $17-19$ & 1 & 3 \\
5 & $26-29$ & 0 & 0 & $20-22$ & 14 & 45 \\
6 & $30-33$ & 2 & 6 & $23-25$ & 1 & 3 \\
\hline Jumlah & & 31 & 100 & & 31 & 100 \\
\hline Sumbryyyyy
\end{tabular}

Sumber: Data primer yang diolah, Tahun 2017

Data pada Tabel 3 diatas menunjukkan bahwa pengalaman terbesar yaitu pada interval 18 - 21 dengan frekuensi sebanyak 22 RTP atau sebesar $71 \%$, sedangkan untuk kelas interval terendah yaitu pada kelas 14 - 17 sebanyak 1 RTP atau sebesar $3 \%$. Rata-rata pengalam petani UPSUS dalam berusahatani kedelai adalah selama 19,6 tahun. Sedangkan petani non UPSUS terbesar yaitu pada interval 20 - 22 dengan frekuensi sebanyak 14 RTP atau $45 \%$, sedangkan untuk kelas interval terendah yaitu pada kelas 17 - 19 dan interval $23-25$ yaitu sebanyak 1 RTP atau sebesar $3 \%$. Rata-rata pengalaman petani Non UPSUS dalam berusahatani kedelai adalah selama 16 tahun.

\section{Gambaran Usahatani Kedelai Peserta dan Non Peserta UPSUS}

Lahan yang digunakan petani peserta program UPSUS untuk kegiatan usahatani tanaman kedelai di daerah penelitian umumnya adalah milik sendiri dengan luas lahan yang ditanami kedelai rata-rata adalah $1 \mathrm{Ha} / \mathrm{RTP}$. Sebagai aspek hulu dalam kegiatan usahatani kedelai diawali dengan pengolahan lahan yang dilakukan secara manual dan secara mekanis menggunakan peralatan mesin seperti Hand traktor, Power tracer, dan mesin rumput. Kegiatan budidaya kedelai didaerah penelitian meliputi kegiatan penanaman benih, penyiangan, pemupukan dan pengendalian hama penyakit. Penanaman dilakukan dengan cara membuat lubang dengan menggunakan tugal kemudian setiap lubang diisi $1-2$ butir benih kedelai. Kegiatan penanaman untuk petani peserta UPSUS dilakukan selama satu hari dengan jumlah tenaga kerja sebanyak 15 orang, sedangkan petani Non UPSUS melakukan kegiatan penanaman selama 2-3 hari dengan tenaga kerja yang digunakan sebanyak 7 orang.

Kegiatan pemupukan untuk petani peserta UPSUS dilakukan sebanyak dua kali yaitu sebelum penanaman dilakukan dengan cara menaburkan pupuk diatas lahan, selanjutnya dilakukan pemupukan susulan setelah tanaman berumur 30

Diterbitkan oleh Program Studi Agribisnis Fakultas Pertanian Universitas Batanghari Jambi Halaman 16 
Jurnal Media Agribisnis Vol. 4 No. 1 Tahun 2019 Hal 10 - 20

Media Komunikasi Hasil Penelitian Bidang Ilmu Agribisnis

ISSN print 2548-7027

ISSN online 2541-6898

hari. Sedangkan untuk petani Non UPSUS kegiatan pemupukan dilakukan hanya satu kali yaitu pada saat sebelum penanaman.

Panen kedelai dilakukan setelah tanaman berumur 110 hari. Hasil panen selanjutnya dipacking menggunakan karung dengan kapasitas seberat 50 $\mathrm{kg} / \mathrm{karung}$. Pemasaran biji kedelai oleh petani peserta program UPSUS didaerah penelitian adalah dengan sistem antar langsung ke perusahaan penadah kedelai dengan harga Rp. 6.500/kg untuk kedelai yang dihasilkan dari petani peserta UPSUS, sedangkan harga kedelai yang dihasilkan oleh petani non UPSUS lebih rendah yaitu sebesar Rp.6000/Kg.

\section{Biaya Produksi}

Rata-rata jumlah komponen biaya-biaya dalam usahatani kedelai untuk petani peserta program UPSUS di daerah penelitian dapat dilihat pada Tabel 4.

Tabel 4 : Rata-rata Komponen Biaya Produksi Petani Sampel Peserta UPSUS dan Non UPSUS untuk Usahatani Tanaman Kedelai Di daerah Rantau Rasau Kabupaten Tanjung Jabung Timur

\begin{tabular}{|l|l|r|r|r|r|}
\hline No. & $\begin{array}{l}\text { Komponen } \\
\text { Biaya Produksi }\end{array}$ & $\begin{array}{l}\text { Jumlah Biaya } \\
\text { (UPSUS) } \\
\text { (Rp/Ha/MT) }\end{array}$ & $\begin{array}{l}\text { Persentase } \\
(\%)\end{array}$ & $\begin{array}{l}\text { Jumlah Biaya } \\
\text { (Non UPSUS) } \\
\text { (Rp/Ha/MT) }\end{array}$ & $\begin{array}{l}\text { Persentase } \\
(\%)\end{array}$ \\
\hline I. & Biaya tetap : & 100.000 & 1,789 & 81.434 & 1.01 \\
1. & Parang & 90.000 & 1,6 & 102.106 & 1,528 \\
2. & Sabit & 250.000 & 4,473 & 225.524 & 4,24 \\
3. & Handsprayer & 45.000 & 0,8 & 43.754 & 0,76 \\
4. & Tampah & 50.000 & 3,354 & 200.743 & 3,279 \\
5. & Terpal & 0,89 & 34.619 & 0,658 \\
6. & Tugal & $\mathbf{7 2 2 . 5 0 0}$ & $\mathbf{1 2 , 9 2 7}$ & $\mathbf{6 8 8 . 1 8 1}$ & $\mathbf{1 1 , 5 1}$ \\
\hline & Jumlah I & & & & \\
II. & Biaya Variabel : & 616.290 & 11,02 & 404.560 & 7,36 \\
1. & Sewa Alsin & 4000000 & 71,57 & 1.382 .623 & 29,886 \\
2. & Upah Tenaga Kerja & & & 480.000 & 9,195 \\
3. & Benih & & & 1.945 .000 & 37,26 \\
4. & Pupuk & 250.000 & 4,473 & 480.000 & 9,195 \\
5. & Obat-obatan & $\mathbf{4 . 8 6 6 . 2 9 0}$ & $\mathbf{8 7 , 0 7}$ & $\mathbf{4 . 9 2 4 . 1 8 2}$ & $\mathbf{8 8 , 4 9}$ \\
6. & Transportasi & $\mathbf{5 . 5 8 8 . 7 9 0}$ & $\mathbf{1 0 0}$ & $\mathbf{5 . 6 3 0 . 3 6 3}$ & $\mathbf{1 0 0}$ \\
\hline & Jumlah II & & &
\end{tabular}

Sumber: Data primer yang diolah, Tahun 2017

\section{Penerimaan}

Rata-rata jumlah hasil produksi, harga produk dan penerimaan petani peserta UPSUS dan Non UPSUS di daerah penelitian dapat dilihat pada Tabel 5. 
Jurnal Media Agribisnis Vol. 4 No. 1 Tahun 2019 Hal 10 - 20

Media Komunikasi Hasil Penelitian Bidang Ilmu Agribisnis

ISSN print 2548-7027

ISSN online $2541-6898$

Tabel 5. Rata-rata Produksi, Harga dan Penerimaan pada Usahatani Kedelai peserta UPSUS dan Non UPSUS di Kecamatan Rantau Rasau Kabupaten Tanjung Jabung Timur Tahun 2017

\begin{tabular}{clcc}
\hline No. & \multicolumn{1}{c}{ Uraian } & UPSUS & Non UPSUS \\
\hline 1 & Produksi $(\mathrm{Kg} / \mathrm{Ha} / \mathrm{MT})$ & $2.206,452$ & 1.129 \\
2 & Harga $(\mathrm{Rp} / \mathrm{Kg})$ & 6.500 & 6.000 \\
3 & Penerimaan $(\mathrm{Rp} / \mathrm{Ha} / \mathrm{MT}$ & 14.341 .935 & 6.886 .794
\end{tabular}

Data Primer yang diolah tahun 2017

Data pada Tabel 5 diatas menunjukkan bahwa produksi kedelai serta jumlah penerimaan untuk petani UPSUS lebih tinggi dibanding petani Non UPSUS. Hal ini disebabkan oleh adanya perbedaan penggunaan pupuk. Petani peserta UPSUS lebih banyak menggunakan pupuk dari pada petani Non UPSUS, sehingga mempengaruhi hasil produksi, sejalan dengan penelitian Busyra, 2018. Perbedaan jumlah pupuk yang digunakan terjadi karena tingginya harga standar pupuk di daerah penelitian, sehingga petani peserta non UPSUS menghemat penggunaan pupuk yang tujuannya untuk memperkecil biaya produksi. Berbeda dengan petani peserta UPSUS, harga pupuk disubsidi dari pemerintah. Penggunaan pupuk akan mempengaruhi hasil panen. Tanaman kedelai yang mendapatkan nutrisi yang cukup dari pupuk akan menghasilkan produksi yang maksimal, sedangkan nutrisi yang kurang mencukupi kebutuhan tanaman akan menurunkan hasil produksi.

\section{Pendapatan Usahatani Tanaman Kedelai}

Rata-rata jumlah penerimaan, biaya produksi dan pendapatan petani sampel di daerah penelitian dapat dilihat pada Tabel 6 .

Tabel 6 . Rata-rata Penerimaan, Biaya Produksi dan Pendapatan Petani Kedelai Peserta UPSUS dan Non UPSUS di Kecamatan Rantau Rasau Kabupaten Tanjung Jabung Timur Tahun 2017

\begin{tabular}{cccc}
\hline \multirow{2}{*}{ No } & \multirow{2}{*}{ Uraian } & Jumlah $(\mathbf{R p} / \mathrm{Ha} / \mathbf{M T})$ \\
\cline { 3 - 4 } & & UPSUS & NON UPSUS \\
\hline 1 & Penerimaan & 14.341 .935 & 6.886 .794 \\
2 & Biaya Produksi & 5.588 .790 & 5.630 .363 \\
3 & Pendapatan & 8.753 .145 & 1.256 .431 \\
\hline
\end{tabular}

Data Primer yang diolah tahun 2017

Berdasarkan hasil uji statistik terhadap data rata-rata pendapatan usahatani kedelai antara petani peserta program UPSUS dengan petani Non UPSUS terdapat perbedaan yaitu terlihat dari nilai $Z_{\text {hitung }}(52,892)>Z_{\text {tabel }}(1,645)$ dengan $a=5 \%$ maka $\mathrm{H}_{0}$ ditolak, dan $\mathrm{H}_{1}$ diterima dengan kaidah keputusan terdapat perbedaan pendapatan usahatani kedelai antara petani peserta UPSUS dengan petani Non UPSUS. 
Jurnal Media Agribisnis Vol. 4 No. 1 Tahun 2019 Hal 10 - 20

Media Komunikasi Hasil Penelitian Bidang Ilmu Agribisnis

ISSN print 2548-7027

ISSN online 2541-6898

\section{KESIMPULAN}

Berdasarkan hasil penelitian dan pembahasan dapat ditarik kesimpulan sebagai berikut :

1. Pendapatan usaha tani kedelai untuk petani peserta UPSUS lebih tinggi dibanding dengan petani Non UPSUS, yaitu rata-rata pendapatan petani UPSUS adalah sebesar Rp. 8.753.145/Ha/MT dan petani Non UPSUS sebesar 1.256.431/Ha/MT.

2. Terdapat perbedaan signifikan antara Pendapatan petani kedelai peserta UPSUS dengan Non UPSUS di Kecamatan Rantau Rasau Kabupaten Tanjung Jabung Timur.

\section{DAFTAR PUSTAKA}

Badan Pusat Statistik Provinsi Jambi, 2015. Jambi Dalam Angka. Badan Pusat Statistik Provinsi Jambi. Jambi

Burhan,U. M, Nitisemito, A. S. 2004. Wawasan Studi kelayakan dan Evaluasi proyek. Penerbit Bumi Aksara. Jakarta.

Busyra, R.G. 2016. Dampak Program Upaya Khusus (Upsus) Padi Jagung Kedelai (Pajale) Pada Komoditas Padi Terhadap Perekonomian Kabupaten Tanjung Jabung Timur. Jurnal Media Agribisnis (MeA) Vol.1 No.1 Tahun 2016

Busyra, R.G. 2018. Dampak Upsus Terhadap Kesejahteraan Petani Kedelai. Jurnal Media Agribisnis (MeA) Vol.3 No.2 Tahun 2018.

David, F.R. 2006. Strategi : Konsep. Edisi Kesepuluh. Jilid 1.Salemba Empat. Jakarta

Dinas Pertanian Tanjabtim - Faperta Unbari (2016). Kajian Tentang Kontribusi Gertak Tanpa Dusta Terhadap Pendapatan Petani. Laporan Akhir.

Febriyastuti R.A. Pujiyono, 2016. Pengaruh Umur, Jumlah Tanggungan Keluarga, Luas Lahan, Pendidikan, Jarak Tempat Tinggal, Dan Keuntungan Terhadap Curahan Waktu Kerja Wanita Tani Sektor Pertanian Di Desa Tajuk Kecamatan Getasan, Kabupaten Semarang. Diponegoro Journa Of Economics 2 (3), 1-14.

Hernanto F. 1996. Ilmu Usaha Tani. Penerbit Swadaya. Jakarta.

Inneke Carolina. 2005. Pengembangan Agroidustri Kerupuk Ikan di kota Jambi (Studi Kasus Pada agroindustri kerupuk ikan "Alamiah"). Skripsi Fakultas Pertanian Universitas Jambi (Tidak di Publikasikan).

Khairuman, Sudenda D. 2004. Budi Daya patin secara Intensif. Penerbit Agromedia Pustaka. Jakarta.

Mubyarto. 1991. Pengantar Ekonomi pertanain. LP3ES, Jakarta.

Mulyadi. 2002. Akuntansi Biaya. BPFE, Yogyakarta.

Nasution M. 2002. Pengembangan Kelembagaan Koperasi Pedesaan Untuk Agroindustri. IPB-Press. Bogor.

Rangkuti, F. 2003. Analisis SWOT Teknik Pembedah Kasus. PT. Gramedia Pustaka Utama. Jakarta.

Reksodiprodjo, 1985. Dasar-Dasar Management. BPFE. Yogyakarta.

Diterbitkan oleh Program Studi Agribisnis Fakultas Pertanian Universitas Batanghari Jambi Halaman 19 
Jurnal Media Agribisnis Vol. 4 No. 1 Tahun 2019 Hal 10 - 20

Media Komunikasi Hasil Penelitian Bidang Ilmu Agribisnis

ISSN print 2548-7027

ISSN online 2541-6898

Salusu, J. 1996. Pengambilan Keputusan Strategik Untuk Organisasi Publik dan Organisasi Non Profit. PT. Gramedia, Jakarta.

Saptari AM. 1993. Sistem Monitoring dan pengendalian penggunaan Investasi dan perdagangan Agroindustri. Makalah pada permodalan Agroindustri. Penerbit Bangkit. Jakarta.

Siagian. 2003. Manajemen Strategik. Bumi Aksara. Jakarta.

Soekartawi. 1994. Teori Ekonomi Produksi dengan pokok Bahasan Analisis Fungsi Cobb Dauglas. PT. Raja Grafindo Persada. Jakarta. . 2001. Pengantar Agroindustri. PT. Raja Grafindo Persada, Jakarta.

Swasha Basu. 2002. Manajemen Pemasaran Modern. BPFE. Yogyakarta.

Syarief R. 1993. Pemilihan dan Penerapan Teknologi Tepat Guna Usaha Agroindustri Buah-buahan Tropis Potensial. Penerbit Bangkit, Jakarta

Tjokoamidjojo B, Mustopadidjaya AR. 1991. Kebijaksanaan dan Administrasi Pembangunan. LP3ES, Jakarta. 